\title{
ANGIOPLASTY UNTUK STENOSIS ATEROSKLEROSIS INTRAKRANIAL
}

\author{
ANGIOPLASTY FOR INTRACRANIAL ATEROSCLEROSIS STENOSIS \\ Tranggono Yudo Utomo ${ }^{1}$ \\ ${ }^{I}$ Staff Pengajar Departemen Neurologi FK UKI Jakarta
}

\begin{abstract}
Intracranial atherosclerotic stenosis (ICAS) is a common cause of transient ischemic attack (TIA) and ischemic stroke which is the second - leading cause of death worldwide. At up to $40-50 \%$, the rate of symptomatic ICAS is significantly higher in the Asian population and is probably the most common cause of stroke worldwide. Indication for endovascular treatment is a challenge and the selection of material as well as interventional techniques essentially differs from the treatment of extracranial stenosed. Conservative (medical and lifestyle change) and endovascular therapy procedures as well as endovascular therapeutic approaches (percutaneous balloon angioplasty (PTA) or stent assisted angioplasty (PTAS) are available for the treatment of ICAS. This review aims to further evaluate the role of angioplasty in treating intracranial atherosclerosis. Endovascular treatment, such as balloon angioplasty with or without stenting, have emerged as therapeutic option for symptomatic intracranial stenosis. There are many types of endovascular techniques available for ICAS treatment, including balloon angioplasty alone, balloon - mounted stent (Pharos Vitesse), and self - expandable stent (Wingspan), each of which has its owns features and specific advantages relating to different intracranial artery lesion. Thus, endovascular treatment in ICAS patient is an alternative to prevent recurrent TIA/ischemic stroke. Endovascular treatment requires comprehensive considerations and multidiscipline team in order to provide effective treatment for ICAS patients.
\end{abstract}

Keywords : Intracranial atherosclerotic stenosis, Angioplasty, Intracranial Atherosclerotic, Intracranial Stenosis

\begin{abstract}
ABSTRAK
Stenosis Aterosklerosis Intrakranial (ICAS) adalah penyebab umum Transient Ischemic Attack (TIA) dan stroke iskemik yang merupakan penyebab kematian nomor dua di dunia. Hingga 40 - 50\%, tingkat ICAS simptomatik secara signifikan lebih tinggi pada populasi Asia dan mungkin merupakan penyebab paling umum dari stroke di seluruh dunia. Indikasi untuk perawatan endovaskular merupakan tantangan dan pemilihan bahan serta teknik intervensi pada dasarnya berbeda dari pengobatan stenosis ekstrakranial. Prosedur konservatif (perubahan medis dan gaya hidup) dan terapi endovaskular serta pendekatan terapi endovaskular (angioplasti balon perkutan (PTA) atau angioplasti stent-assisted (PTAS)) tersedia untuk perawatan ICAS. Tinjauan pustaka ini bertujuan untuk menevaluasi peran angioplasty sebagai tatalaksana dari stenosis aterosklerosis intrakranial. Perawatan endovaskular, seperti balloon angioplasty dengan atau tanpa stenting, telah muncul sebagai pilihan terapeutik untuk stenosis intrakranial simtomatik. Ada banyak jenis teknik endovaskular yang tersedia untuk perawatan ICAS, termasuk balloon angioplasty, ballon - mounted stent (Pharos Vitesse), dan self - expandable stent (Wingspan), masing-masing memiliki fitur dan keunggulan spesifik yang berkaitan dengan lesi arteri intrakranial yang berbeda. Maka dari itu, terapi endovascular pada pasien ICAS dapat dipertimbangkan sebagai alternatif untuk mencegah TIA/stroke iskemik berulang. Tindakan endovaskular membutuhan pertimbangan yang komprehensif dan persiapan multidisiplin agar dapat memberikan pelayanan yang efektif untuk pasien.
\end{abstract}

Kata Kunci : Stenosis Aterosklerosis Intrakranial, Angioplasty, Aterosklerosis Intrakranial, Stenosis Intrakranial 


\section{PENDAHULUAN}

Stenosis aterosklerotik intrakranial (ICAS) adalah salah satu penyebab paling umum dari stroke di seluruh dunia dan dikaitkan dengan risiko tinggi stroke berulang dibandingkan dengan stroke lainnya. ICAS sangat sering terjadi pada populasi kulit hitam, Asia, Hispanik, India, dan beberapa negara Arab yang menunjukkan bahwa angka kejadian ICAS cenderung meningkat karena populasi terus berkembang. Stenosis dari cabang utama seperti arteri serebral medial dan arteri vertebralis merupakan faktor terpenting penyebab stroke di dunia. Stenosis parah dari $70 \%$ sampai $99 \%$ memiliki $25 \%$ risiko untuk terjadi stroke berulang setiap tahun bahkan setelah terapi farmakologis yang adekuat. ${ }^{1,2}$

Stenosis lebih dari $60 \%$ terbukti memiliki gangguan status hemodinamik yang menyebabkan stroke berulang atau TIA sekitar $7 \%$ pada tahun pertama diagnosis. Karena itu pasien dengan ICAS yang berat, masih perlu balloon angioplasty dan pemasangan stent di pusat kesehatan meskipun dengan pengobatan yang tepat. ${ }^{3,4}$

Sampai saat ini, manajemen medis yaitu terapi antiplatelet, mengkontrol faktor risiko, serta manajemen gaya hidup, merupakan terapi lini pertama untuk ICAS yang berguna untuk mencegah transient ischemic (TIA) dan stroke iskemik berulang. ${ }^{5}$

Clopidogrel in High-risk patients with Acute Non-disabling Cerebrovascular Events (CHANCE) menunjukkan bahwa clopidogrel ditambah aspirin cenderung menurunkan risiko stroke berulang pada stroke ringan dan TIA pada pasien dengan ICAS dibandingkan dengan aspirin saja, tetapi perbedaan tersebut tidak signifikan secara statistik. Cilostazol juga gagal menunjukkan keberhasilan yang signifikan untuk mencegah perkembangan ICAS dan lesi iskemik baru. ${ }^{6,7}$

Manajemen medis sendiri tidak cukup untuk mencegah terjadinya serangan berulang pada pasien yang mengalami intrakranial stenosis simptomatik. Terapi endovaskular seperti ballon angioplasty, merupakan opsi untuk intrakranial stenosis simptomatik sejak tahun 1980. Meskipun angioplasti intrakranial memiliki risiko komplikasi yang tinggi pada awalnya, namun teknologi baru tentang neurointerventional meningkatkan tingkat keberhasilan cara ini. ${ }^{4,8}$ Kemajuan dalam teknologi memungkinkan prosedur endovaskular yang lebih aman dengan tingkat keberhasilan yang lebih baik. Angioplasti intrakranial dapat dilakukan pada pasien dengan risiko tinggi dan prognosis buruk hanya jika mendapatkan terapi farmakologis. ${ }^{3,4}$ Tinjauan pustaka ini bertujuan untuk 
mengevaluasi peran angioplasti sebagai tatalaksana dari ICAS.

\section{PEMBAHASAN}

Stenosis Aterosklerosis Intrakranial (ICAS)

Stenosis aterosklerotik intrakranial simtomatik (ICAS) dianggap sebagai salah satu penyebab utama stroke iskemik di seluruh dunia dengan prevalensi yang jauh lebih tinggi pada orang Asia hingga 30 sampai $50 \%$ dibandingkan Kaukasia dan menyebabkan risiko tinggi kambuhnya stroke. ${ }^{4,10}$

Meskipun dengan manajemen medis intensif, risiko tinggi TIA dan stroke berulang masih diamati pada pasien dengan ICAS simtomatik (70-99\%). Kelompok pasien ini dianggap refrakter terhadap terapi medis agresif. Data dari uji coba Stenting and Aggressive Medical Management for Preventing Recurrent stroke in Intracranial Stenosis (SAMMPRIS) menunjukkan bahwa tingkat stroke 1 tahun atau kematian sebesar $12,6 \%$ pada pasien ICAS simtomatik dengan derajat stenosis lebih dari $70 \% .^{9,11}$

Stenosis dengan penyempitan luminal lebih dari $70 \%$ pada arteri intrakranial besar mengarah ke $20 \%$ risiko lebih tinggi terkena stroke berikutnya dalam 1 tahun, seperti percobaan yang ditunjukkan oleh WarfarinAspirin Symptomatic Intracranial Disease (WASID); walaupun setelah dirawat dengan aspirin, pasien dalam uji coba WASID masih menunjukkan kejadian stroke iskemik berulang yang tinggi. Prevalensi ICAS sebesar 46,6\% pada populasi Cina, berdasarkan penelitian Chinese Intracranial Atheroscklerosis (CICAS). Dalam studi CICAS, pasien dengan ICAS mengalami stroke yang lebih parah dan rawat inap yang lebih lama dibandingkan tanpa ICAS. Oleh karena itu, diperlukan intervensi yang efektif untuk mencegah stroke pada pasien dengan ICAS, terutama pada mereka dengan ICAS yang bergejala. Ahli saraf biasanya menyarankan pasien dengan ICAS yang bergejala menerima percutaneous transluminal angioplasty and stenting (PTAS) untuk mencegah stroke. ${ }^{12,13}$

Manajemen ICAS dapat dilakukan dengan menggunakan balloon angioplasty dengan atau tanpa stent intrakranial. Okada dkk, melaporkan hasil dari 47 pasien dengan stenosis arteri serebral medial bergejala yang menjalani balloon angioplasty tanpa pemasangan stent. Tingkat keberhasilan prosedur ini sebesar 95,7\%; dengan kejadian stroke dan mortalitas 30 hari pasca prosedur masing-masing sebesar $6,4 \%$ dan $2,1 \%$. $^{3,14}$

\section{Balloon Angioplasty}

Balloon angioplasty merupakan terapi endovaskular pertama dan paling sederhana 
yang digunakan untuk pengobatan stenosis intrakranial, yang meningkatkan perfusi dari wilayah hilir arteri stenotik dengan melebarkan kaliber segmen stenotik, menurunkan atau menghilangkan gejala neurologis yang sedang berlangsung atau berulang, dan berpotensi menunda atau mencegah oklusi sekunder dan stroke. Sundt dkk, melaporkan kasus sukses pertama balloon angioplasty transluminal untuk pasien dengan aterosklerotik, arteri basilar stenotik tingkat tinggi, yang refrakter terhadap terapi antikoagulan, dimana hasil angiografi dan klinis jangka pendek sangat baik. ${ }^{11,12}$

Balloon angioplasty efektif dalam pengobatan stenosis koroner melalui kompresi dan diseksi dari plak aterosklerotik di dinding pembuluh darah, namun ada komplikasi dari pengobatan ini. Komplikasi ini terjadi karena pelebaran plak merusak endotel menyebabkan bahan trombogenik (terutama kolagen) masuk ke darah yang bersirkulasi dan menyebabkan trombotik dan obstruksi dari aliran darah. ${ }^{11,12}$

Dengan bertambahnya kasus stenosis intrakranial dengan balloon angioplasty, komplikasi periprosedural juga dilaporkan, seperti diseksi arteri dengan konsekutif trombosis atau ruptur, residual stenosis akibat sekuestrasi atau pembengkakan pembuluh darah, dan oklusi vaskular akut atau subakut karena pembentukan hematoma dinding.
Risiko tinggi komplikasi menyebabkan perkembangan teknologi baru dari balloon angioplasty. Balloon angioplasty submaksimal dengan inflasi yang lambat dikembangkan dan direkomendasikan sebagai tindakan yang tepat untuk stenosis intrakranial. Dalam penelitian dari 41 konsekutif simtomatik, tingkat tinggi $(\geq 70 \%)$ pasien ICAS, diberi pengobatan balloon angioplasty submaksimal. Tingkat kejadian 30 hari dan angka kelangsungan hidup perioperatif dan iskemik selama 1 tahun adalah 4,9 dan 91\%, keduanya lebih baik dari orang-orang dari kelompok medis dan PTAS dalam uji coba SAMMPRIS. Baru-baru ini, percobaan fase I prospektif dari 24 pasien dengan stenosis intrakranial yang signifikan diobati dengan balloon angioplasty submaksimal juga melaporkan hasil keamanan yang lebih baik, tanpa 30 hari stroke iskemik di daerah pembuluh stenotik yang diobati dan hasil yang baik, termasuk rekurensi 1 tahun tingkat stroke sebesar $5,55 \%$ dan tidak ada kejadian kematian atau perdarahan. Penggunaan teknik dan peralatan terkini, intracranial balloon angioplasty dapat dilakukan dengan aman dan efisien pada pasien dengan ICAS yang simtomatik. ${ }^{11,12,15}$

Balloon angioplasty tanpa stent dilakukan dengan pertimbangan perforasi pembuluh darah. Bagaimanapun pemasangan stent mungkin masih dibutuhkan pada stenosis berat. $^{12,16}$ 


\section{Balloon-Mounted Stent}

Pada tahap awal pemasangan stent intrakranial, sebagian besar balloon-mounted stent yang digunakan untuk pengobatan pasien ICAS simtomatik adalah stent koroner, yang tidak dirancang untuk pembuluh darah intrakranial dan dengan demikian sulit untuk dimasukkan melalui pembuluh darah servikal dan intrakranial yang berliku-liku. ${ }^{11,17}$ Oleh karena itu, pemasangan balloon-mounted stent sering terjadi distorsi anatomi regional dan terkadang menyebabkan cedera traumatis pada segmen vaskular yang berliku karena kekakuan dan kurangnya kesesuaian dari balon kateter lumen ganda bertekanan tinggi. Sementara itu, balloon-mounted stent menuntut ekspansi yang lebih besar untuk mengembangkan lumen tetapi tidak memiliki kekuatan ekspansi intrinsik, yang dapat meningkatkan risiko kerusakan perforasi akibat pergeseran plak saat lesi dekat atau di lokasi perforasi arteri. Dengan kemajuan stent intrakranial, berbagai jenis intrakranial balloon-mounted stent telah dikembangkan untuk pengobatan ICAS simtomatik. ${ }^{18,19}$ Meskipun sebagian kekurangan intrakranial balloon-mounted stent masih ada, balloonmounted stent memiliki keuntungan dalam beberapa aspek. Pertama, stenosis bisa membengkak dalam satu langkah oleh satu operator. Kedua, kekuatan radial yang digunakan cukup kuat untuk menahan fenomena recoil yang dihasilkan oleh plak atau dinding pembuluh darah. Ketiga, kemungkinan penempatan stent yang tepat ditingkatkan, yang menjaga stent panjang pendek dan menghindari penutupan segmen pembuluh normal. Studi registri INTRASTENT yang membandingkan balloon-mounted stent dengan self-expandable stent pada 409 pasien ICAS yang simtomatik melaporkan tidak ada perbedaan yang signifikan secara statistik dalam tingkat komplikasi, tetapi balloon-mounted stent cenderung lebih tinggi risiko stroke perforator, sedangkan self-expandable stent cenderung untuk menyebabkan lebih banyak peristiwa tromboemboli. Penelitian terbaru membandingkan hasil jangka pendek stenting pada 97 pasien dengan stenosis arteri vertebrobasilar intrakranial simptomatik menunjukkan bahwa balloon-mounted stent memiliki tingkat residu stenosis yang lebih rendah dan lebih cocok untuk pasien dengan akses arteri halus dan stenosis pendek dan konsentris (lesi Mori A) dibandingkan selfexpandable stent. ${ }^{11,20}$

Mengingat tingkat residu stenosis adalah salah satu faktor utama yang mempengaruhi restenosis, residu stenosis yang lebih sedikit dengan lebih menguntungkan untuk pencegahan restenosis. 


\section{Self-Expendable Stent}

Satu-satunya self-expendanle stent yang tersedia (Wingspan) telah menjadi stent intrakranial yang paling banyak digunakan untuk pengobatan ICAS sejak mendapat persetujuan FDA. Dalam praktek klinis, balloon angioplasty submaksimal dilakukan sebelum pemasangan stent. ${ }^{12,17}$ Karena sistem stent Wingspan lebih fleksibel dan lebih mudah melewati pembuluh darah intrakranial yang berliku daripada sistem balloon-mounted stent, stent ini memiliki tingkat keberhasilan teknis yang lebih tinggi. ${ }^{21}$ Sistem Wingspan stent memiliki risiko infark perforator yang lebih rendah, karena angioplasti dapat dikurangi ukurannya sehingga meminimalkan risiko terhadap pembuluh utama normal yang letaknya berdekatan. Gaya radial keluar yang kecil dari self-expendanle stent mengurangi gaya kompresi yang dikirim ke plak dekat arteri perforasi. ${ }^{22}$ Keuntungan dari selfexpendanle stent ini telah membuat penggunaannya lebih umum dalam pengobatan ICAS. Namun, desain self-expendanle stent masih memiliki banyak kekurangan. Di satu sisi, manuver dua langkahnya dapat memperpanjang durasi prosedur, yang berpotensi meningkatkan risiko stroke emboli, di sisi lain, manuver pertukaran wire dapat meningkatkan risiko perdarahan subaraknoid karena gerakan yang tidak disengaja dan tidak terkontrol dari guide-wire tip. ${ }^{17}$ Dalam hal tingkat restenosis, self-expendanle stent lebih rendah daripada balloon-mounted stent. Studi terhadap 46 lesi pada 45 pasien ICAS yang simtomatik dengan terapi antitrombotik yang gagal, diterapi dengan stent Wingspan. Hasil penelitian menunjukkan bahwa tingkat restenosis (didefinisikan lebih dari 50\% dari inisial lumen) adalah 42,8, 9,5\% di antaranya adalah dengan gejala. ${ }^{17}$

\section{KESIMPULAN}

Stenosis aterosklerotik intrakranial (ICAS) merupakan penyebab umum dari transient ischemic attack (TIA) dan stroke iskemik. Pengobatan endovaskular, termasuk balloon angioplasty, balloon-mounted stents, dan selfexpandable stent placement dipertimbangkan sebagai pilihan alternatif untuk pencegahan TIA berulang atau stroke iskemik pada pasien dengan ICAS.

Pengobatan endovaskular pada pasien yang dipilih dengan cermat, pemilihan individual subtipe pengobatan endovaskular, dan tim multidisiplin yang berpengalaman mengelola pasien dalam periode pra-, peri- dan pascaprosedur berpotensi untuk memberikan 
pengobatan yang aman dan efektif untuk pasien dengan ICAS yang simtomatik.

\section{DAFTAR PUSTAKA}

1. Gorelick PB, Wong KS, Bae HJ, Pandey DK. Large artery intracranial occlusive disease: a large worldwide burden but a relatively neglected frontier. Stroke. 2008; 39: 2396-99.

2. Hussain M, Datta N, Cheng $Z$, et al. Spanning from the West to East: An Updated Review on Endovascular Treatment of Intracranial Atherosclerotic Disease. Aging Dis. 2017;8(2):196-202.

3. Usman FS, Soetanto GW, Ramadhoni PD, Hermawan GA. Numbers of stent and balloon in neuro-endovascular procedures was associated with numbers of stroke risk factors in Indonesia. J Neuro Inter. 2020.

4. Wabnitz A, Chimowitz M. Angioplasty, Stenting and Other Potential Treatments of Atherosclerotic Stenosis of the Intracranial Arteries: Past, Present and Future. J Stroke. 2017 Sep;19(3):271-6.

5. Chimowitz MI, Lynn MJ, Derdeyn CP, Turan TN, Fiorella D, Lane BF, et al. Stenting versus aggressive medical therapy for intracranial arterial stenosis. $N$ Engl $J$ Med. 2011: 365:993-1003.

6. Liu L, Wong KSL, Leng X, et al. Dual antiplatelet therapy in stroke and ICAS: subgroup analysis of CHANCE. Neurology 2015; 85: 1154-1162.

7. Uchiyama S, Sakai N, Toi S, et al. Final results of cilostazol-aspirin therapy against recurrent stroke with intracranial artery stenosis (CATHARSIS). Cerebrovasc Dis Extra 2015; 5: 1-13.

8. Gomez CR, Orr SC. Angioplasty and stenting for primary treatment of intracranial arterial stenoses. Arch Neurol 2001;58:1687-1690.

9. Sangha RS, Naidech AM, Corado C, Ansari SA, Prabhakaran S. Challenges in the Medical Management of Symptomatic
Intracranial Stenosis in an Urban Setting. Stroke. 2017 Aug 1;48(8):2158-63.

10. Nordmeyer $\mathrm{H}$, Chapot R, Aycil A, Stracke CP, Wallocha M, Hadisurya MJ, et al. angioplasty and stenting of intracranial arterial stenosis in perforator-bearing segments: a comparison between the anterior and the posterior circulation. Frontiers in neurology. 2018.

11. Lou J, Wang T, Gao P, Krings T, Jiao L. Endovascular treatment of intracranial atherosclerotic stenosis: current debates and future prospects. Frontiers in Neurol. 2018.

12. Padalia A, Sambursky JA, Skinner C, Moureiden M. Percutaneous Transluminal Angioplasty with Stent Placement versus Best Medical Therapy Alone in Symptomatic Intracranial Arterial Stenosis: A Best Evidence Review. Cureus. 10(7):e2988.

13. Cui XP, Lin M, Mu JS, Ye JX, He WQ, $\mathrm{Fu} \mathrm{ML}$, et al. Angioplasty and stenting for patients with symptomatic intracranial atherosclerosisi: study protocol of a randomised controlled trial. BMJ. 2016: 6 .

14. Okada H, Terada T, Tanaka Y, et al. Reappraisal of Primary Balloon Angioplasty without Stenting for Patients with Symptomatic Middle Cerebral Artery Stenosis. Neurol Med Chir(Tokyo). 2015;55(2):133-40.

15. Dumont TM, Sonig A, Mokin M, Eller JL, Sorkin GC, Snyder KV, et al. Submaximal angioplasty for symptomatic intracranial atherosclerosis: a prospective phase I study. J Neurosurg. (2016) 125:964-71.

16. Wang Y, Ma Y, Gao P, et al. Primary angioplasty without stenting for symptomatic, high-grade intracranial stenosis with poor circulation. Am $\mathbf{J}$ Neuroradiol. 2018;39(8):1487-92.

17. Chatterjee AR, Derdeyn CP. Stenting in intracranial stenosis: current controversies and future directions. Curr Atheroscler Rep. 2015;17:48. 
18. Kang K, Zhang Y, Shuai J, Jiang C, Zhu $\mathrm{Q}$, Chen K, et al. Balloon-mounted stenting for ICAS in a multicenter registry study in China: a comparison with the WEAVE/WOVEN trial. J Neurointerventional Surg. 2020 Dec 11;neurintsurg-2020-016658.

19. Kurre W, Brassel F, Bruning R, Buhk J, Eckert B, Horner S, et al. Complication rates using balloon-expandable and selfexpanding stents for the treatment of intracranial atherosclerotic stenoses: analysis of the INTRASTENT multicentric registry. Neuroradiology. 2012;54:43-50.

20. Liu L, Zhao X, Mo D, Ma N, Gao F, Miao Z. Stenting for symptomatic intracranial vertebrobasilar artery stenosis: 30-day results in a highvolume stroke center. Clin Neurol Neurosurg. 2016;143:132-8.

21. Ding D, Liu KC. Applications of stenting for intracranial atherosclerosis. Neurosurg Focus. 2011;30:E15.

22. Maier IL, Karch A, Lipke C, Behme D, Mpotsaris A, Kabbasch C, et al. Transluminal angioplasty and stenting versus conservative treatment in patients with symptomatic basilar artery stenosis: perspective for future clinical trials. Clin Neuroradiol. (2016) 28:33-38. 